\title{
Old debates rekindled as world AIDS rates escalate
}

Experts in AIDS research, ethics, law and policy quietly met in Geneva mid-July to debate whether sponsors of HIV prevention trials are obligated to provide treatment to people who become infected during the trials. This has been a contentious issue-some experts advocate providing the most-proven therapy, whereas e others are content limiting it to the highest level of care available in the host country.

"There is a responsibility of these sponsors to provide triple therapy [in the case of breakthrough infections]," says José Esparza, coordinator of the World Health Organization's HIV vaccine initiative. "Three years ago, we were still debating whether antiretrovirals should be made available to developing countries—today, that is gone," Esparza says.

Esparza's view tallies with most of the conference's participants, except those of the UK Medical Research Council (MRC) and the US National Institutes of Health (NIH). The NIH bility for treatment on host nations (Nat. Med. 9, 629; 2003).

The NIH and the MRC are "stuck back in 1997, 1996," says Ruth Macklin, an ethicist at Albert Einstein College of Medicine in New York. "It's kind of a little narrow view: 'don't expect us to provide treatment for these people when the research is over," she says. However, 윽 is developing a policy that places the responsi- the NIH's HIV Vaccine Trials Network, a collaborative effort with other organizations, is developing a standard-of-care policy more in line with the conference's consensus.

Previous arguments-such as lack of funds-to preclude standard-of-care treatment for those infected in vaccine trials are no

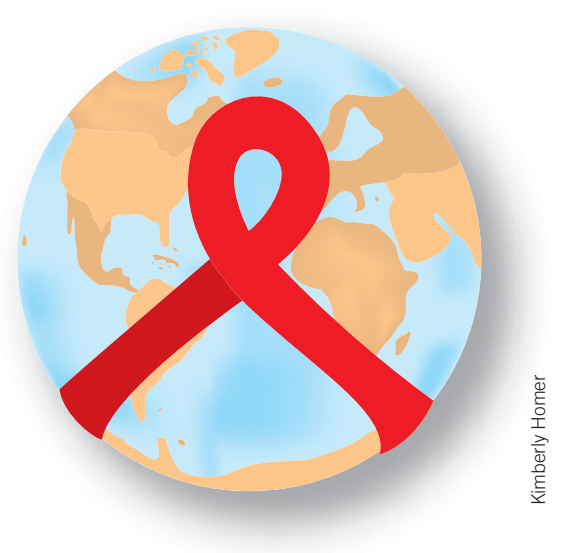

longer valid, experts point out. There are monies available from the Global Fund to Fight AIDS, Tuberculosis and Malaria, the World Bank, the $\$ 15$ billion Bush administration AIDS initiative (Nat. Med. 9, 808; 2003) and possible funding by a trial's sponsor. If all else fails, there may be a special grant or insur- ance fund set up as a safety net, says Esparza.

Discussions on preventing HIV infection take on special weight as reports emerge that AIDS rates are once again on the upswing in many parts of the world, including the US, Australia, Canada and Europe. Experts warn that South Africa (see News, page 1098), with 4.7 million infected people, will soon see a sharp rise in AIDS-related fatalities as its epidemic enters the 'death phase'.

The Indian government also recently admitted that as many as 4.58 million of its citizens may be infected with HIV. "India and South Africa now have the dubious distinction of competing for first place [in number of HIV infections]," Esparaza notes.

India's health minister Shushma Swaraj has recently been a big proponent of the $\mathrm{ABC}$ (abstinence, being faithful and condom use) program of abstinence favored by the Bush administration. Some Indian officials also maintain that there is no basis for the estimate that there will be 25 million HIV cases in India by 2010. But after widespread media attention to India's AIDS problem, Prime Minister Vajpayee has agreed to convene a special session of Parliament to chart legislation on AIDS prevention.

Myrna Watanabe, New York and K.S. Jayaraman, New Delhi

\section{New malaria drug to be unveiled in Africa}

A new antimalarial drug, the product of a public-private partnership initiated by UK researchers, will soon hit the market in African countries. The drug, dubbed lapdap, was approved by the UK's Medicines and Healthcare Products Regulatory Agency in August and will be available this fall in subSaharan Africa.

"I think there is a lot of promise in [lapdap] and I think it's going to be a stronger drug than Fansidar," says Thomas Wellems, head of the malaria genetics section at the US National Institutes of Health.

Fansidar has been the drug of choice for public health systems in Africa since chloroquine resistance began to spike more than 10 years ago. In some regions, however, clinical failure rates for Fansidar are as high as $25 \%$, and the alternatives are relatively expensive and out of reach for many Africans. Lapdap targets the same pathway in the Plasmodium falciparum parasite as Fansidar, but it clears much faster from the body, so there is less opportunity for the parasite to develop resistance.
As part of the partnership, GlaxoSmithKline agreed to public-sector price controls that would keep the drug about as cheap as Fansidar. William Watkins, a researcher at the University of Liverpool, and his colleagues had that in mind in the mid-1990s when they initiated the partnership, which also includes the Tropical Disease Research Programme of the World Health Organization (WHO/TDR) and the UK government (Nat. Med. 7, 389; 2001).

Because Fansidar resistance rose rapidly, however, WHO/TDR is wary of widespread use of lapdap in the public sector, and no African government has yet signed up to buy it, says Watkins. According to Allan Schapira, WHO's coordinator for the Roll Back Malaria initiative, the agency's policy is to minimize the risk of resistance by promoting the use of combination therapies, such as lapdap with artesunate. The combination is currently being tested in phase 2 clinical trials.

A number of other antimalarial drugs in the pipeline are products of public-private partnerships, including the Medicines for Malaria

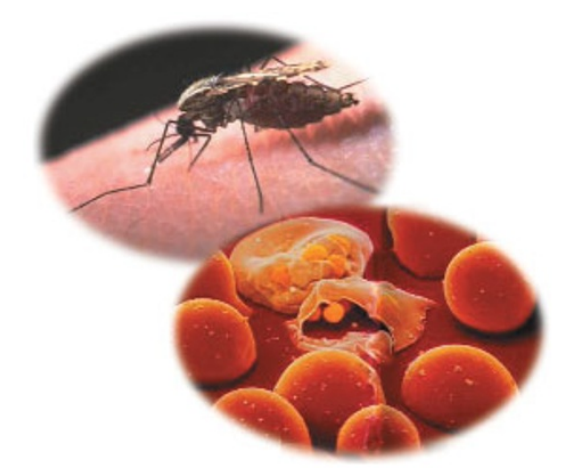

Deadly disease: Malaria, which destroys red blood cells, claims 1 million lives in Africa each year.

Venture. Many of those new drugs are also to be used in combination with artesunate or related compounds. Some researchers are working on synthetic compounds that could cheaply substitute for artesunate, and others are developing drugs that target a variety of pathways, including the one used by chloroquine.

Charlotte Schubert, New York 